\title{
Refractory Metal Oxide-Doped Titanate Nanotubes: Synthesis and Photocatalytic Activity under UV/Visible Light Range
}

\author{
Min-Sang Kim ${ }^{1,2}$, Hyun-Joo Choi ${ }^{3}$, Tohru Sekino ${ }^{4}{ }^{\mathbb{D}}$, Young-Do Kim ${ }^{1}$ and Se-Hoon Kim ${ }^{2, *}$ \\ 1 Department of Materials Science \& Engineering, Hanyang University, Seoul 04763, Korea; \\ mskim1@katech.re.kr (M.-S.K.); ydkim1@hanyang.ac.kr (Y.-D.K.) \\ 2 Metallic Material R\&D Center, Korea Automotive Technology Institute, Cheonan-si 31214, Korea \\ 3 School of Materials Science and Engineering, Kookmin University, Seoul 02707, Korea; \\ hyunjoo@kookmin.ac.kr \\ 4 SANKEN, The Institute of Scientific and Industrial Research, Osaka University, Mihogaoka 8-1, Ibaraki, \\ Osaka 567-0047, Japan; sekino@sanken.osaka-u.ac.jp \\ * Correspondence: shkim@katech.re.kr; Tel.: +82-41-559-3377
}

check for updates

Citation: Kim, M.-S.; Choi, H.-J.; Sekino, T.; Kim, Y.-D.; Kim, S.-H. Refractory Metal Oxide-Doped Titanate Nanotubes: Synthesis and Photocatalytic Activity under UV/Visible Light Range. Catalysts 2021, 11, 987. https://doi.org/ $10.3390 /$ catal11080987

Academic Editors: Danilo Russo and Dionissios Mantzavinos

Received: 30 July 2021

Accepted: 15 August 2021

Published: 18 August 2021

Publisher's Note: MDPI stays neutral with regard to jurisdictional claims in published maps and institutional affiliations.

Copyright: (c) 2021 by the authors. Licensee MDPI, Basel, Switzerland. This article is an open access article distributed under the terms and conditions of the Creative Commons Attribution (CC BY) license (https:/ / creativecommons.org/licenses/by/ $4.0 /)$.

\begin{abstract}
This study synthesized refractory metal-oxide-doped titanate nanotubes (TNTs) using a hydrothermal process and investigated their photocatalytic activity under ultraviolet and visible light irradiation. Refractory metal doping ions such as $\mathrm{Mo}^{6+}$ and $\mathrm{W}^{6+}$ can be supplied from molybdenum oxide and tungsten oxide sources. The refractory metal-doped TNT may act as an electron trap or enhance the adsorption capacity, which increases the number of active sites and promotes separation efficiency.
\end{abstract}

Keywords: titanate; hydrothermal process; refractory metal; doping; photocatalytic activity

\section{Introduction}

A photocatalyst is a substance that promotes a chemical reaction through photochemical reactions from external light energy. Electrons and holes generated by the absorption of external light energy reach the surface of the photocatalyst, causing chemical reactions such as oxidation or reduction with other substances [1]. As a result of these characteristics, photocatalysis is of great importance in solving global energy and environmental issues. Highly active photocatalytic materials are capable of converting solar energy, exploiting it for the degradation of organic pollutants in air and water, and the conversion of gases and liquids [2-4]. Among the various materials with photocatalytic properties, $\mathrm{TiO}_{2}$ is believed to be the most promising because of the (i) high photocatalytic activity stemming from its wide band gap, (ii) low cost owing to its natural abundance and nontoxicity, and (iii) long-term stability stemming from its chemical stability [5].

Recently, one-dimensional $\mathrm{TiO}_{2}$ nanostructures (titania nanotubes, TNTs) have attracted much attention because of their unique physicochemical properties. Various modern and classical methods have been reported to produce TNTs [6-20], which includes replica- or template-assisted method [9-12], template-less methods via a solution chemical synthesis [13-15], hydrothermal treatment [16,17], and electrochemical anodic oxidation [18-20]. Each method has its advantages and disadvantages, and researchers may select a suitable method based on the target. For example, template-assisted methods have the benefit of producing highly aligned structures, and electrochemical anodic oxidation processes can produce high-quality TNTs with a high specific surface area, enhanced charge carrier transfer, and a large number of active sites. Among these, hydrothermal methods, first reported by Kasuga et al. [7,14], are preferable because of their simple and cost-effective setup, environmental friendliness, and high reactivity, which are suitable for large-scale production. Despite such advantages, the practical applications of $\mathrm{TiO}_{2}$ as photocatalysts are extremely limited because of its poor absorption capability under the 
visible light range ( $>400 \mathrm{~nm}$ ), which originates from its intrinsically large energy band gap and low quantum yield caused by the rapid recombination of photo-generated electrons and holes [21,22]. Therefore, several $\mathrm{TiO}_{2}$ modification studies have been proposed, including composites with $\mathrm{TiO}_{2}$ and other semiconductors with low band gap energy [23,24], metal-ion-doped $\mathrm{TiO}_{2}$ using transition metals [25], and non-metal-doped $\mathrm{TiO}_{2}$ [26,27].

Among these studies, metal-ion-doped $\mathrm{TiO}_{2}$ is known to be the most effective method for improving photocatalytic activity under visible irradiation and stably maintaining these properties. Refractory metal doping is considered a promising approach to improve the photocatalytic activity of $\mathrm{TiO}_{2}$ under visible light irradiation. Among the refractory metals, niobium $(\mathrm{Nb})$, molybdenum $(\mathrm{Mo})$, and tungsten $(\mathrm{W})$ can easily form solid solutions in the lattice of $\mathrm{TiO}_{2}$ because the ionic radii of $\mathrm{Nb}^{5+}(0.64 \AA), \mathrm{Mo}^{6+}(0.59 \AA)$, and $\mathrm{W}^{6+}(0.64 \AA)$ are similar to that of $\mathrm{Ti}^{4+}(0.605 \AA)$ [28-30].

In previous research [31], $\mathrm{Nb}$-doped titanate nanotube (TNT) structures with improved photocatalytic activity have been synthesized successfully using a hydrothermal process with $\mathrm{TiO}_{2}$ and $\mathrm{Nb}_{2} \mathrm{O}_{5}$ powders. The Nb-TNT nanostructures have a smaller band gap energy of $3.24 \mathrm{eV}$ than that of pure TNTs $(3.34 \mathrm{eV})$. Moreover, regarding photocatalytic activity, the Nb-TNTs show properties 1.4-3.1 times higher than those of pure TNTs.

In this study, to improve the reactivity under visible light irradiation, we synthesize Mo-TNT and W-TNT structures through a hydrothermal process using economical $\mathrm{TiO}_{2}$ and $\mathrm{MoO}_{3}$ and $\mathrm{WO}_{3}$ powders as the Mo and $\mathrm{W}$ precursors, respectively. The microstructure and photocatalytic activity of the synthesized refractory metal-doped TNTs are also investigated.

\section{Results and Discussion}

Figure 1 shows the XRD patterns of the pure TNT, Mo- and W-doped TNT samples. All the samples exhibited peaks only for TNTs (monoclinic $\mathrm{H}_{2} \mathrm{Ti}_{4} \mathrm{O}_{9} \cdot \mathrm{H}_{2} \mathrm{O}$, JCPDS 36-655) without revealing the presence of any oxides; $\mathrm{H}_{2} \mathrm{Ti}_{n} \mathrm{O}_{2 n+1}$ or $\mathrm{Na}_{x} \mathrm{H}_{2-\mathrm{x}} \mathrm{Ti}_{n} \mathrm{O}_{2 n+1}(\mathrm{n}=3,4)$ is known to be formed in pure TNTs fabricated by an alkaline hydrothermal method [15]. The XRD results confirmed that the TNT prepared from $\mathrm{TiO}_{2}$ powder was synthesized successfully by the hydrothermal process; $\mathrm{MoO}_{3}$ and $\mathrm{WO}_{3}$ peaks were not detected in the patterns, meaning that the $\mathrm{MoO}_{3}$ and $\mathrm{WO}_{3}\left(\mathrm{Mo}^{6+}\right.$ and $\mathrm{W}^{6+}$ ions, respectively) were dissolved in the TNT lattice. In addition, the peak for the (200) plane at $2 \theta \sim 10^{\circ}$ was not present in the XRD patterns of Mo- and W-TNTs. Loading of Mo or W on the surface of TNTs may deform the crystalline structure of the surface layer [32,33], weakening the intensity of the peak for the (200) plane [1]. Furthermore, the peak for the (200) plane of TNTs might not be clearly detected when its intensity is small (for the case of Mo- or Wdoped TNTs) because of the significant background noise (swelling of the spectra) typically presenting in the extremely low 2 theta ranges.

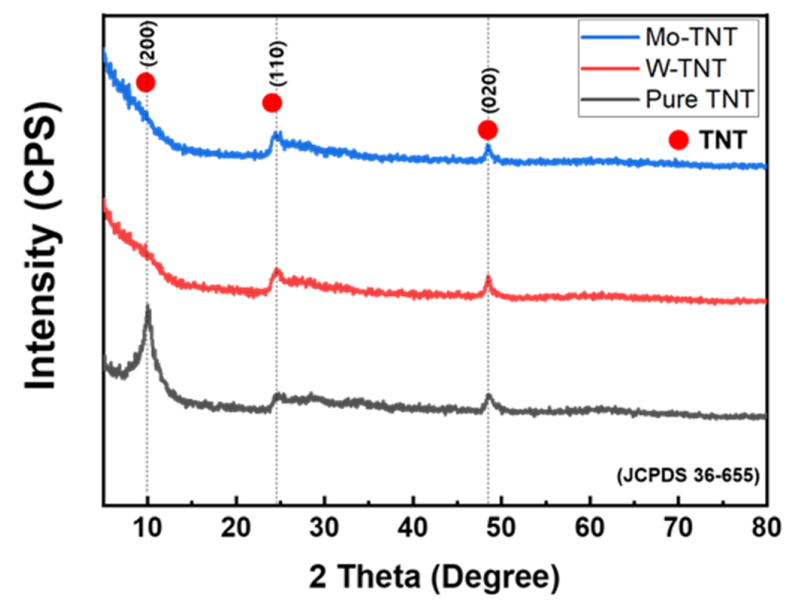

Figure 1. XRD patterns of synthesized Pure TNT, Mo-TNT, and W-TNT. 
Figure 2 shows the high-resolution XPS spectra of pure TNTs and synthesized Moand W-doped TNTs. Figure 2a shows the XPS Ti $2 p$ spectrum whose two peaks at about $458-464 \mathrm{eV}$ correspond to the Ti $2 \mathrm{p}_{3 / 2}$ and Ti $2 \mathrm{p}_{1 / 2}$ states, indicating that Ti is present in a valence state of $4^{+}$. Figure $2 \mathrm{~b}$ shows the one peak of XPS O $1 \mathrm{~s}$ spectrum at $529 \mathrm{eV}$, which is attributed to oxygen bonded to titanium (Ti-O). XPS spectra of W-doped TNTs, shown in Figure $3 c$, shows one peak at about $37 \mathrm{eV}$ correspond to the $\mathrm{W} 4 \mathrm{f}_{5 / 2}$ state, confirming that $\mathrm{W}$ is present in the $6^{+}$valence state [34]. Furthermore, in the XPS spectra of Mo doped TNTs, one peak at about $232 \mathrm{eV}$ agree with the Mo $3 \mathrm{~d}_{5 / 2}$ state is indicated that Mo is present in the $6^{+}$valence state [35].
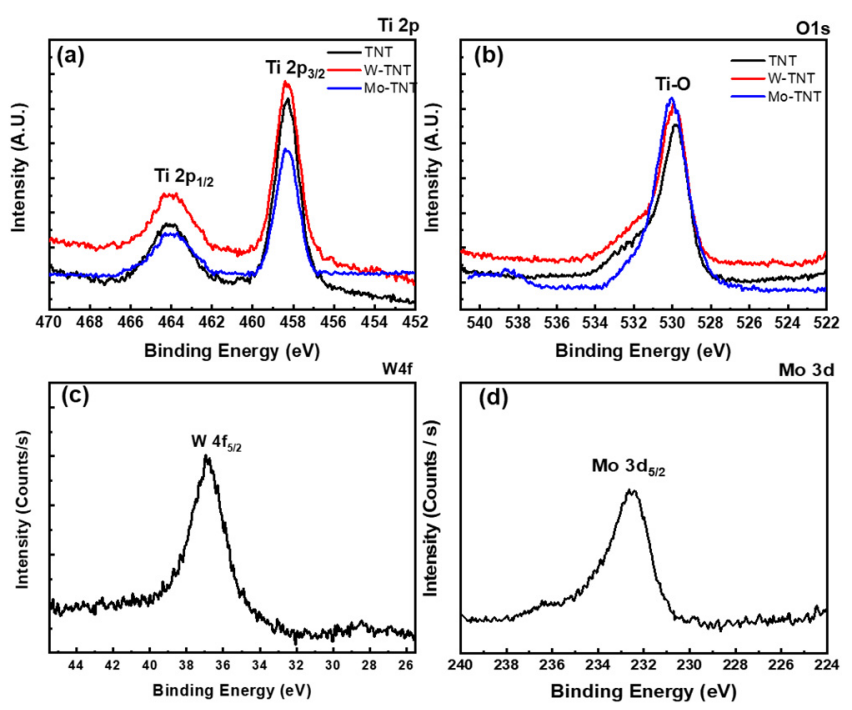

Figure 2. High-resolution XPS spectra of pure TNTs and synthesized Mo, W-doped titanate nanostructures, which confirms the presence of (a)Ti 2p, (b) O 1s, (c) W 4f, (d) Mo 3d.
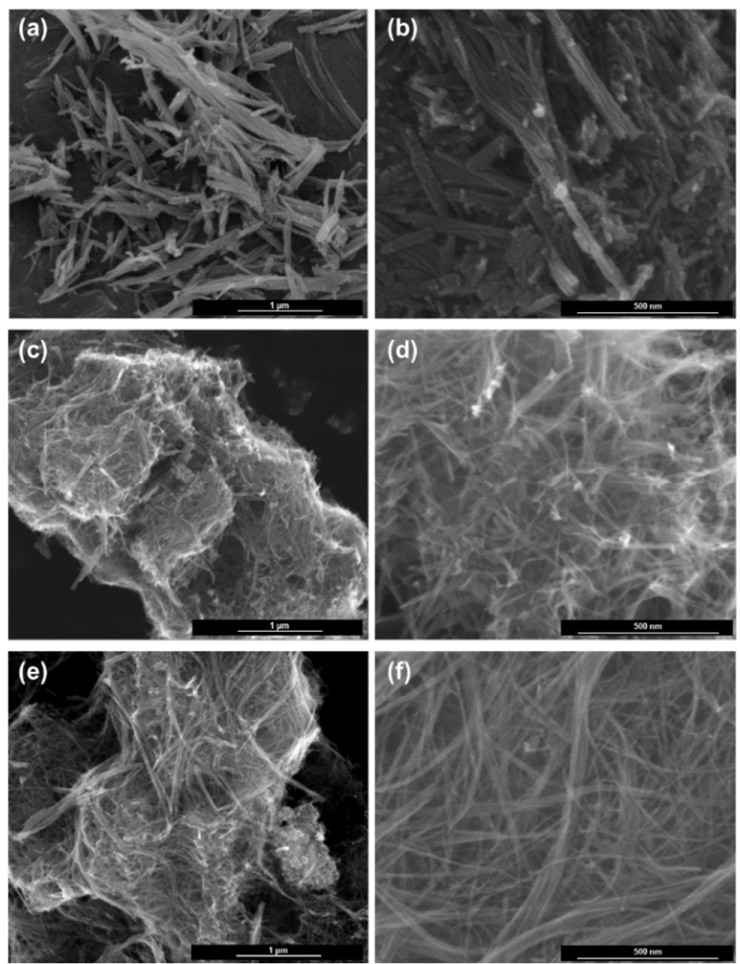

Figure 3. FE-SEM images of synthesized pure TNT nanostructures: (a) low and (b) high magnification. Mo-TNT nanostructures: (c) low and (d) high magnification. W-TNT nanostructures: (e) low and (f) high magnification. 
Figure 3 shows the FE-SEM images of the as-synthesized pure TNT, Mo-TNT, and $\mathrm{W}$-TNT samples. The pure TNTs were bundled together in numbers ranging from several tens to several hundreds. The outer diameter and length of each pure TNT sample was $\sim 10 \mathrm{~nm}$ and $1 \mu \mathrm{m}$, respectively. As seen in Figure 3, it was confirmed that the as-synthesized Mo-TNT and W-TNT structures also had a larger aspect ratio than pure TNT, with an outer diameter of $\sim 10 \mathrm{~nm}$ and a length of several $\mu \mathrm{m}$.

Figure 4 shows the TEM images of the as-synthesized pure TNT, Mo-TNT, and WTNT samples. The figure clearly shows that Mo-TNT and W-TNT samples had more agglomerated nanotube structure than pure TNT, and the W-TNT sample had a longer nanotube length than the Mo-TNT sample. Although the formation mechanism of pure TNT in NaOH aqueous solution has been argued by some researchers until now, many researchers agree that the titanate nanosheets formed during hydrothermal process are rolled to nanotube [36-38]. It is considered that the reason the aggregation occurred only in the Mo-TNT and W-TNT is that $\mathrm{Mo}^{6+}$ and $\mathrm{W}^{6+}$ are dissolved in the TNT lattice and slight lattice distortion occurred. Because of the slight lattice distortion, when the titanate nanosheet is rolled to nanotube, it is fabricated as a curved shape, which is considered to have caused agglomeration.
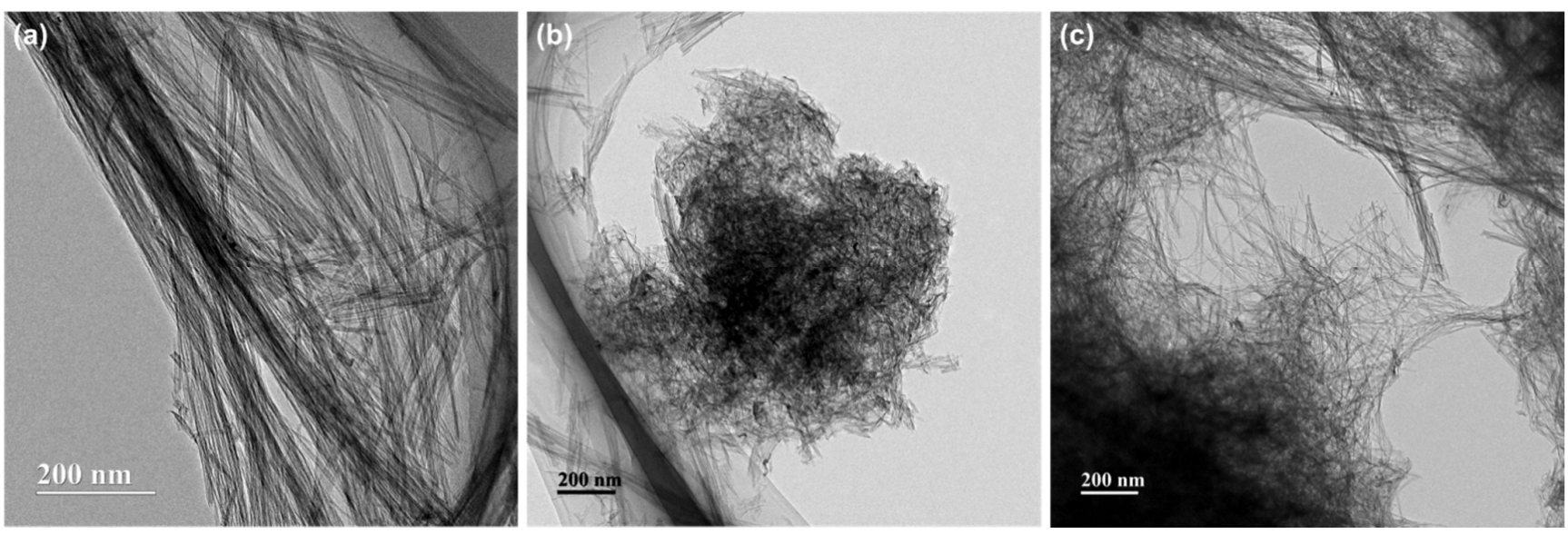

Figure 4. TEM images of synthesized (a) Pure TNT, (b) Mo-TNT, and (c) W-TNT nanostructures.

Figure 5 shows the UV-vis diffuse reflectance spectra and Tauc plot of the band gap energy of the pure TNT and synthesized Mo-TNT and W-TNT nanostructures. As shown in Figure 5a, the reflectance of the synthesized Mo- and W-TNTs presented a relatively shifted reflectance compared with that of the pure TNT and a low reflectance in the visible light region around $560 \mathrm{~nm}$. Moreover, as shown in the Tauc plot of Figure 5b, the band gap energy of pure TNTs, Mo-TNTs, and W-TNTs was 3.34, 3.32, and $3.32 \mathrm{eV}$, respectively. The band gap energy of the pure TNTs $(3.34 \mathrm{eV})$ analyzed was in agreement with results of other research studies [39], and the Mo- and W-TNTs were shown to have a band gap energy similar to that of pure TNTs. 

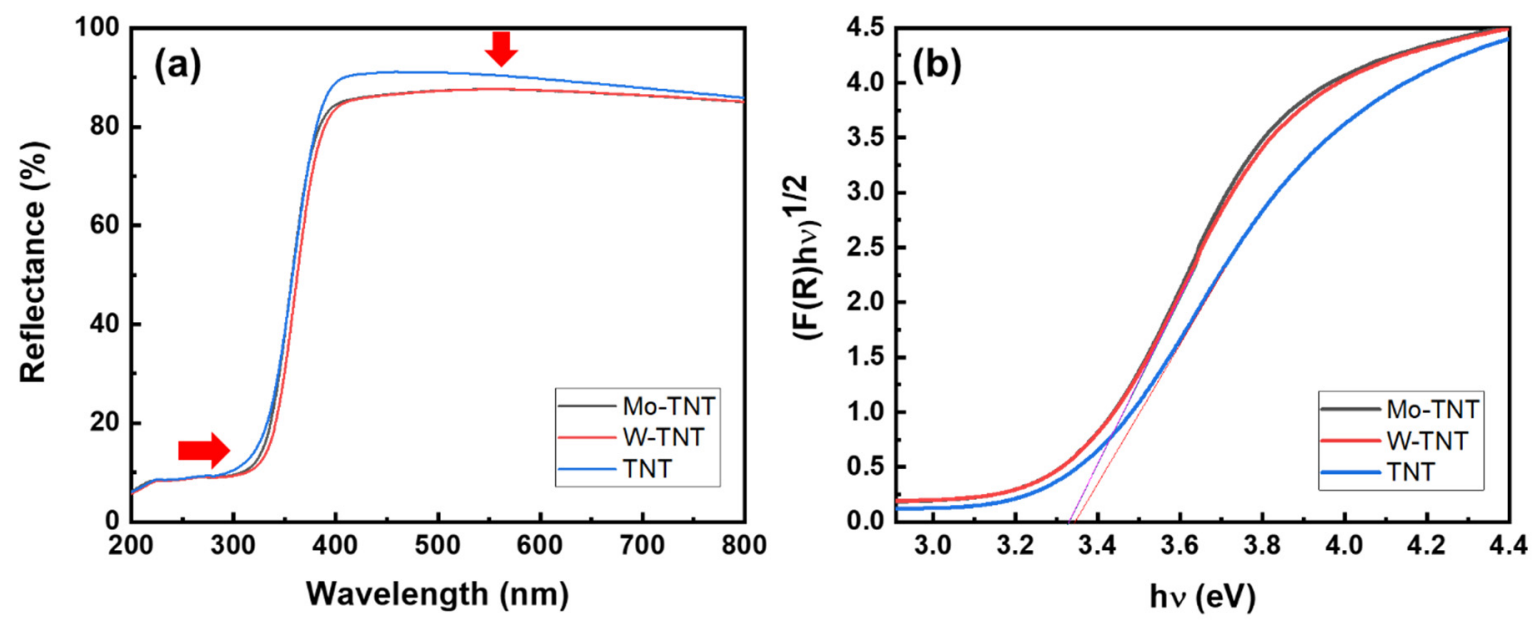

Figure 5. (a) UV-vis diffuse reflectance spectra and (b) Tauc plot for band gap energy of pure TNT, synthesized Mo-TNT, and W-TNT nanostructures.

To evaluate the photocatalytic activity of the synthesized pure TNTs, Mo-TNTs, WTNTs, and commercial P-25 nanopowder, an MB and RhB removal test was conducted under UV-vis light irradiation conditions. Figure 6 shows a schematic depiction of the photocatalytic activity of the refractory-doped TNTs in this study. Theoretically, the reaction starts when enough photons (hv) from the light source hit the electron in the valence band. The electron excites the conduction band, leaving holes in the valence band. Both electrons and holes migrate to the surface of the photocatalyst, oxidizing water to form hydroxyl radicals. Electrons donate to oxygen, forming metal ions that are reduced to their lower valence state and deposited on the photocatalyst surface. During the photocatalytic activity, the refractory dopant may act as a trapping site for excitation and delay the recombination of the excited electrons as well as an active site to enhance the reaction kinetics. Figure $7 \mathrm{a}, \mathrm{b}$ show the degradation properties of MB by pure TNTs, P-25, and synthesized Mo-TNT and W-TNT nanostructures under UV and visible irradiation, while Figure $7 \mathrm{c}, \mathrm{d}$ depict the degradation properties of RhB. The Mo-TNTs and W-TNTs exhibited faster degradation at $\sim 30$ min both under UV and visible irradiation than pure TNT and P25 in the MB solution. In particular, that degradation by refractory metal-doped TNTs was increased significantly under UV and visible light irradiation compared with that of the pure TNTs. It is known that the photocatalytic activity is affected by the electron-hole pair recombination rate within the semiconductor and that the recombination rate of TNT is faster than that of $\mathrm{TiO}_{2}$ in the UV light range [37]. Additionally, it was observed that the commercial P-25 composed of $\mathrm{TiO}_{2}$ did not exhibit photocatalytic activity in visible light irradiation, while the synthesized TNTs did. This also confirmed that the doped metal ions as $\mathrm{Mo}^{6+}$ and $\mathrm{W}^{6+}$ play a major role to enhance the photocatalytic activities. These doping ions create vacancies or excess ions and/or aliovalent cations, resulting in the enhancement of the photocatalytic activity by restraining the electron-hole pair recombination. It is well known that the RhB dye used in Figure $7 \mathrm{c}, \mathrm{d}$ is not adsorbed easily by the catalyst. Thus, the degradation rate of RhB by photocatalytic activity was slower than that of MB. In this case, the enhancement of photocatalytic activity by $\mathrm{Mo}^{6+}$ and $\mathrm{W}^{6+}$ doping was significant under visible light while it was negligible under UV light irradiation. 


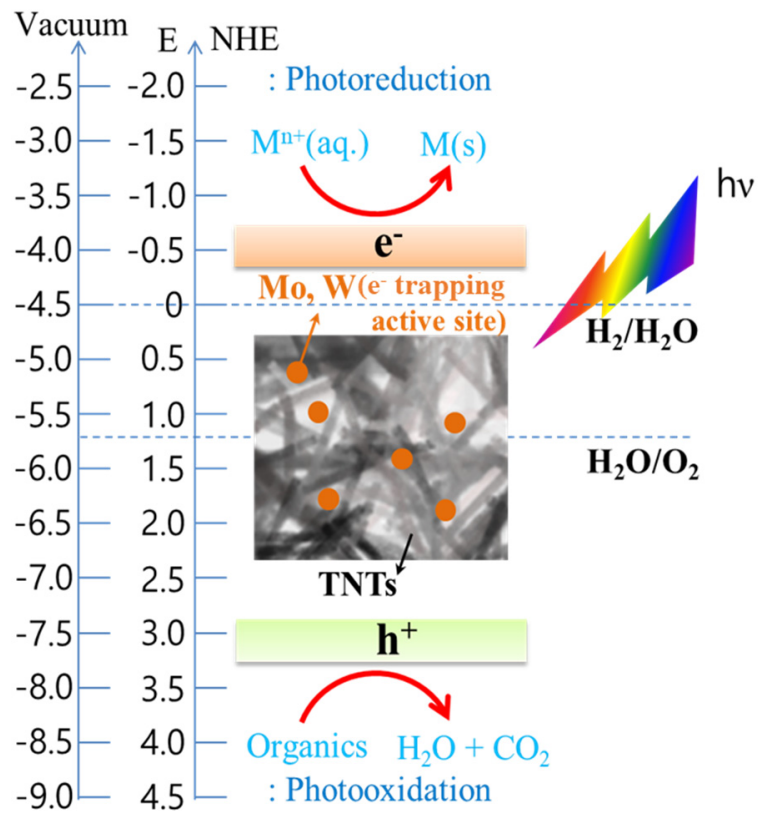

Figure 6. Schematic depiction of the photocatalytic activity of the refractory-doped TNTs.

(a)

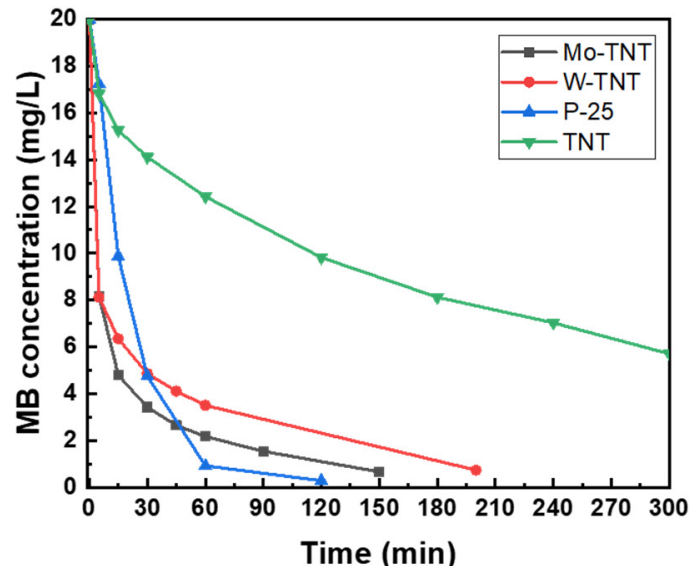

(c)

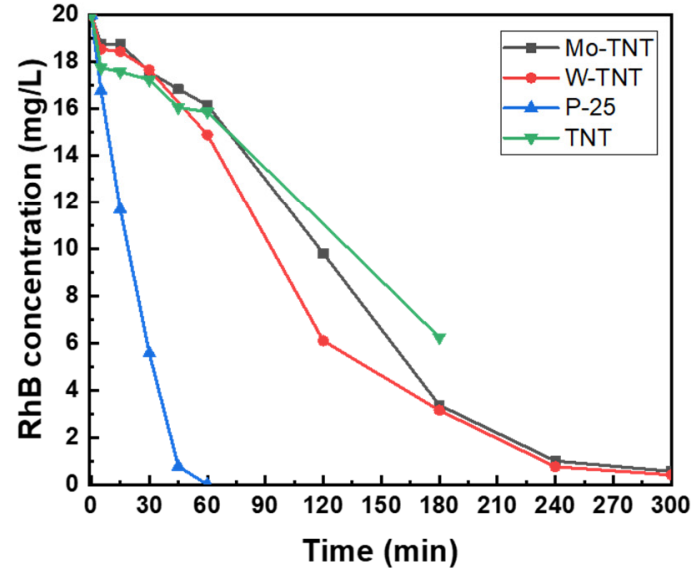

(b)

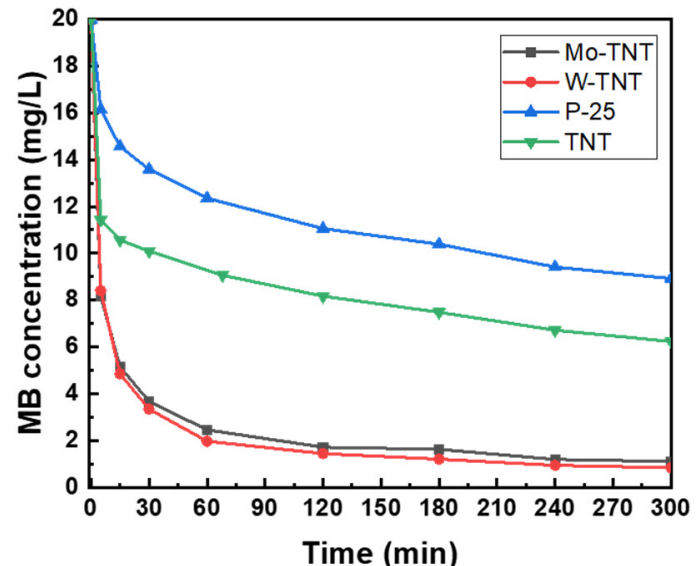

(d)

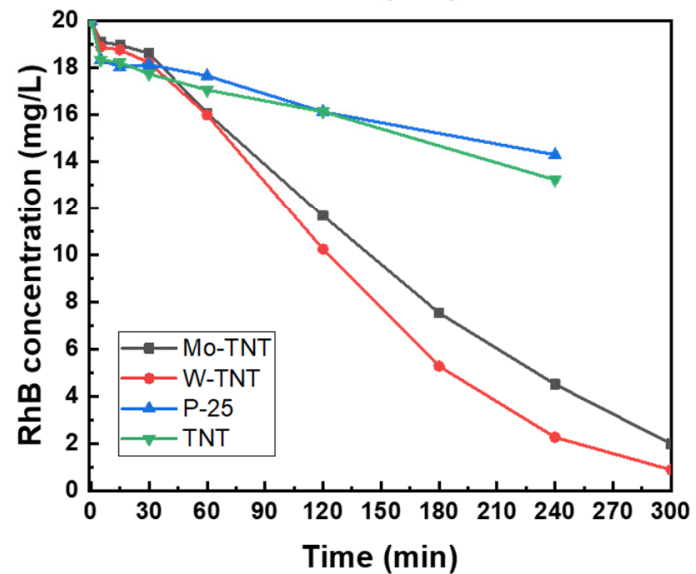

Figure 7. Photocatalytic activity of synthesized Mo-TNT and W-TNT nanostructures under UV-vis light irradiation: (a) MB degradation under UV light irradiation; (b) MB degradation under visible light irradiation; (c) RhB degradation under UV light irradiation; and (d) RhB degradation under visible light irradiation. 


\section{Materials and Methods}

\subsection{Sample Preparation}

The TNTs were synthesized using the hydrothermal process reported by Kasuga et al. [7]. Commercial anatase-phase $\mathrm{TiO}_{2}$ (99.9\%, Kojundo Chemical Lab. Co., Saitama, Japan), $\mathrm{MoO}_{3}$, and $\mathrm{WO}_{3}$ (99.9\%, FUJIFILM Wako Pure Chemical Co., Osaka, Japan) powders were used as the starting materials: $\mathrm{MoO}_{3}$ and $\mathrm{WO}_{3}$ of 1 mol.\% were mixed with $\mathrm{TiO}_{2}$ powder, and the mixed powders were dispersed in a $10-\mathrm{M} \mathrm{NaOH}$ aqueous solution by ultrasonification for $30 \mathrm{~min}$. Subsequently, for TNT synthesis, the mixture was bathed in silicone oil (Shinetsu KF-54) preheated to $120^{\circ} \mathrm{C}$ for $24 \mathrm{~h}$ and stirred with a magnetic stirrer. The resultant product was washed with DI water until it reached $\mathrm{pH} 7-8$. Next, it was treated with $0.1 \mathrm{M} \mathrm{HCl}$ to exchange sodium ions with hydrogen ions before being washed repeatedly with DI water until the conductivity reached $5 \mu \mathrm{S} / \mathrm{cm}$. Finally, the synthesized powder was dried in an oven at $70^{\circ} \mathrm{C}$ for $48 \mathrm{~h}$.

\subsection{Analysis of Phase and Microstructures}

The phase analysis of the synthesized samples was conducted using a powder X-ray diffractometer (XRD; D8 Advance, Bruker AXS GmbH, Karlsruhe, Germany) using Cu K $\alpha$ radiation. Field-emission scanning electron microscopy (FE-SEM) images were acquired using Nova NanoSEM 450 (Thermo Fisher Scientific, Hillsboro, OR, USA). The microstructure observations and composition analyses were performed using transmission electron microscopy (TEM; JEM-2100F, JEOL Ltd., Tokyo, Japan). The optical properties were analyzed with an ultraviolet-visible (UV-vis) spectrophotometer (V-650 spectrophotometer, Jasco Co., Tokyo, Japan) equipped with an integrating sphere accessory for diffuse reflectance spectra; $\mathrm{BaSO}_{4}$ was used as a reference.

\subsection{Characterization of Photocatalytic Activity}

The adsorption and degradation properties of the TNT and refractory metal-doped TNT samples were analyzed using methylene blue (MB; FUJIFILM Wako Pure Chemical Co., Osaka, Japan) and rhodamine B (RhB; FUJIFILM Wako Pure Chemical Co., Osaka, Japan) solutions prepared at a concentration of $20 \mathrm{mg} / \mathrm{L}$. Approximately $20 \mathrm{mg}$ of catalyst was dispersed in $100 \mathrm{~mL}$ of solution. The $\mathrm{MB}$ and $\mathrm{RhB}$ degradations under UV light were evaluated by UV light irradiation (UVF-204S, SAN-EI Electric Co. Ltd., Osaka, Japan), while the degradations under visible light (solar simulator with a cutoff glass filter under $400 \mathrm{~nm}$, HAL-C100, Asahi spectra, Tokyo, Japan) were evaluated by exposing visible light at room temperature. The MB and RhB solutions were then analyzed with a UVvis spectrophotometer (UV mini-1240, Shimadzu Co., Kyoto, Japan) by measuring the absorption bands at 663 and $552 \mathrm{~nm}$, respectively.

\section{Conclusions}

In this study, refractory metal-doped TNT nanostructures were synthesized successfully by a hydrothermal process from $\mathrm{TiO}_{2}$ and $\mathrm{MoO}_{3} / \mathrm{WO}_{3}$ sources, and they exhibited improved photocatalytic activity under UV-vis light irradiation. FE-SEM and HR-TEM results showed that Mo-TNT and W-TNT samples had more agglomerated nanotube structure than pure TNT, and the W-TNT sample had a longer nanotube length than the Mo-TNT sample. To evaluate the photocatalytic effect of refractory metal-doped TNTs, a removal test in the MB and RhB solution under UV-vis light irradiation was conducted, which confirmed that photocatalytic activity of refractory metal-doped TNTs was significantly enhanced under both UV and visible light irradiation compared with the pure TNTs. The refractory metal-doped TNT may act as an electron trap or enhance the adsorption capacity, which increases the number of active sites and promotes the separation efficiency. 
Author Contributions: Conceptualization, S.-H.K., H.-J.C. and T.S.; methodology, M.-S.K. and S.-H.K.; validation, H.-J.C., Y.-D.K., T.S. and S.-H.K.; formal analysis, M.-S.K., H.-J.C. and S.-H.K.; investigation, M.-S.K. and S.-H.K.; resources, Y.-D.K. and T.S.; data curation, M.-S.K.; writingoriginal draft preparation, M.-S.K.; writing - review and editing, H.-J.C. and S.-H.K.; visualization, M.-S.K. and H.-J.C.; supervision, S.-H.K.; project administration, S.-H.K.; funding acquisition, S.-H.K. All authors have read and agreed to the published version of the manuscript.

Funding: This work has supported by the National Research Foundation of Korea (NRF) grant funded by the Korea government (MSIT) (No.2020M3H4A3106736).

Data Availability Statement: Data sharing not applicable to this article as no datasets were generated or analysed during the current study.

Conflicts of Interest: The authors declare no conflict of interest.

\section{References}

1. Byun, J.M.; Park, C.W.; Kim, Y.I.; Kim, Y.D. Photocatalytic activity of rutile $\mathrm{TiO}_{2}$ powder coupled with anatase $\mathrm{TiO}_{2}$ nanoparticles using surfactant. J Korean Powder Metall. Inst. 2018, 25, 257-262. [CrossRef]

2. Fu, C.; Li, M.; Li, H.; Li, C.; Wu, X.; Yang, B. Fabrication of Au nanoparticle/ $\mathrm{TiO}_{2}$ hybrid films for photoelectrocatalytic degradation of methyl orange. J. Alloys Compd. 2017, 692, 727-733. [CrossRef]

3. Mor, G.K.; Shankar, K.; Paulose, M.; Varghese, O.K.; Grimes, C.A. Use of highly-ordered $\mathrm{TiO}_{2}$ nanotube arrays in dye-sensitized solar cells. Nano Lett. 2006, 6, 215-218. [CrossRef]

4. Zhang, W.; Liu, Y.; Li, W.; Liang, W.; Yang, F. Au nanocrystals decorated $\mathrm{TiO}_{2}$ nanotube arrays as anode material for lithium ion batteries. Appl. Surf. Sci. 2019, 476, 948-958. [CrossRef]

5. Xu, H.; Vanamu, G.; Nie, Z.; Konishi, H.; Teredla, R.; Phillips, J.; Wang, Y. Photocatalytic oxidation of a volatile organic component of acetaldehyde using titanium oxide nanotubes. J. Nanomater. 2006, 2006, 78902. [CrossRef]

6. Hoyer, P. Formation of a titanium dioxide nanotube array. Langmuir 1996, 12, 1411-1413. [CrossRef]

7. Kasuga, T.; Hiramatsu, M.; Hoson, A.; Sekino, T.; Niihara, K. Formation of titanium oxide nanotube. Langmuir 1998, 14, 3160-3163. [CrossRef]

8. Chao, W.; Huiqing, F.; Xiaohu, R.; Yun, W.; Weijia, W. Highly dispersed PtO nanodots as efficient co-catalyst for photocatalytic hydrogen evolution. Appl. Surf. Sci. 2018, 462, 423-431.

9. Imai, H.; Takei, Y.; Shimizu, K.; Matsuda, M.; Hirashima, H. Direct preparation of anatase $\mathrm{TiO}_{2}$ nanotubes in porous alumina membranes. J. Mater. Chem. 1999, 9, 2971-2972. [CrossRef]

10. Sekino, T.; Okamoto, T.; Kasuga, T.; Kusunose, T.; Nakayama, T.; Niihara, K. Synthesis and properties of titania nanotube doped with small amount of cations. Key Eng. Mater. 2006, 317-318, 251-254. [CrossRef]

11. Michailowski, A.; AlMawlawi, D.; Cheng, G.; Moskovits, M. Highly regular anatase nanotubule arrays fabricated in porous anodic templates. Chem. Phys. Lett. 2001, 349, 1-5. [CrossRef]

12. Liu, S.M.; Gan, L.M.; Liu, L.H.; Zhang, W.D.; Zeng, H.C. Synthesis of single-crystalline $\mathrm{TiO}_{2}$ nanotubes. Chem. Mater. 2002, 14, 1391-1397. [CrossRef]

13. Eder, D.; Windle, A.H. Carbon-Inorganic Hybrid Materials: The Carbon-Nanotube/ $\mathrm{TiO}_{2}$ Interface. Adv. Mater. 2008, 20, 1787-1793. [CrossRef]

14. Kasuga, T.; Hiramatsu, M.; Hoson, A.; Sekino, T.; Niihara, K. Titania nanotubes prepared by chemical processing. Adv. Mater. 1999, 11, 1307-1311. [CrossRef]

15. Tacchini, I.; Anson-Casaos, A.; Yu, Y.; Martinez, M.T.; Lira-Cantu, M. Hydrothermal synthesis of $1 \mathrm{D}$ TiO 2 nanostructures for dye sensitized solar cells. Mater. Sci. Eng. B 2012, 177, 19-26. [CrossRef]

16. Wang, W.; Lu, C.; Ni, Y.; Su, M.; Xu, Z. Hydrothermal synthesis and enhanced photocatalytic activity of flower-like TiO ${ }_{2}$ on carbon nanotubes. Mater. Lett. 2012, 79, 11-13. [CrossRef]

17. Duong, T.T.; Nguyen, Q.D.; Hong, S.K.; Kim, D.; Yoon, S.G.; Pham, T.H. Enhanced photoelectrochemical activity of the TiO $2 / \mathrm{ITO}$ nanocomposites grown onto single-walled carbon nanotubes at a low temperature by nanocluster deposition. Adv. Mater. 2011, 23, 5557-5562. [CrossRef] [PubMed]

18. Antony, R.P.; Mathews, T.; Dasgupta, A.; Dash, S.; Tyagi, A.K.; Raj, B. Rapid breakdown anodization technique for the synthesis of high aspect ratio and high surface area anatase $\mathrm{TiO}_{2}$ nanotube powders. J. Solid State Chem. 2011, 184, 624-632. [CrossRef]

19. Wang, L.; Wu, X.; Zhang, S. Electrochemical properties of highly ordered $\mathrm{TiO}_{2}$ nanotube arrays as an anode materials for lithium-ion batteries. Appl. Mech. Mater. 2012, 130-134, 1281-1285. [CrossRef]

20. Gong, D.; Grimes, C.A.; Varghese, O.K.; Hu, W.; Singh, R.S.; Chen, Z.; Dickey, E.C. Titanium oxide nanotube arrays prepared by anodic oxidation. J. Mater. Res. 2001, 16, 3331-3334. [CrossRef]

21. Fujishima, A.; Rao, T.N.; Tryk, D.A. Titanium dioxide photocatalysis. J. Photochem. Photobiol. C Photochem. Rev. 2000, 1, 1-21. [CrossRef] 
22. Mohapatra, S.K.; Misra, M.; Mahajan, V.K.; Raja, K.S. Design of a highly efficient photoelectrolytic cell for hydrogen generation by water splitting: Application of $\mathrm{TiO}_{2}-x \mathrm{Cx}$ nanotubes as a photoanode and $\mathrm{Pt} / \mathrm{TiO}_{2}$ nanotubes as a cathode. J. Phys. Chem. C 2007, 111, 8677-8685. [CrossRef]

23. Wang, J.; Han, X.; Zhang, W. Controlled growth of monocrystalline rutile nanoshuttles in anatase $\mathrm{TiO}_{2}$ particles under mild conditions. Cryst. Eng. Comm. 2009, 11, 564-566. [CrossRef]

24. Tian, B.; Li, C.; Zhang, J. One-step preparation, characterization and visible-light photocatalytic activity of $\mathrm{Cr}^{-\mathrm{doped}} \mathrm{TiO} \mathrm{O}_{2}$ with anatase and rutile bicrystalline phases. Chem. Eng. J. 2012, 191, 402-409. [CrossRef]

25. Kim, H.C.; Han, J.K. Synthesis and photo catalytic activity of $10 \mathrm{wt} \%: 20 \mathrm{wt} \% \mathrm{Li}^{-\mathrm{TiO}_{2}}$ composite powders. J. Korean Powder Metall. Inst. 2016, 23, 33-37. [CrossRef]

26. Chen, X.; Kuo, D.H.; Lu, D. N-doped mesoporous $\mathrm{TiO}_{2}$ nanoparticles synthesized by using biological renewable nanocrystalline cellulose as template for the degradation of pollutants under visible and sun light. Chem. Eng. J. 2016, 295, 192-200. [CrossRef]

27. Liu, Y.; Chen, X.; Li, J.; Burda, C. Photocatalytic degradation of azo dyes by nitrogen-doped $\mathrm{TiO}_{2}$ nanocatalysts. Chemosphere 2005, 61, 11-18. [CrossRef] [PubMed]

28. Shannon, R.D. Revised effective ionic radii and systematic studies of interatomic distances in halides and chalcogenides. Acta Crystallogr. A 1976, 32, 751-767. [CrossRef]

29. Corbel, G.; Laligant, Y.; Goutenoire, F.; Suard, E.; Lacorre, P. Effects of partial substitution of Mo6+ by Cr6+ and W6+ on the crystal structure of the fast oxide-ion conductor structural effects of W6+. Chem. Mater. 2005, 17, 4678-4684. [CrossRef]

30. Kletzin, A.; Adams, M.W.W. Tungsten in biological systems. FEMS Microbiol. Rev. 1996, 18, 5-63. [CrossRef] [PubMed]

31. Byun, J.M.; Choi, H.R.; Kim, Y.D.; Sekino, T.; Kim, S.H. Photocatalytic activity under UV/Visible light range of Nb-doped titanate nanostructures synthesized with $\mathrm{Nb}$ oxide. Appl. Surf. Sci. 2017, 415, 126-131. [CrossRef]

32. Yang, D.; Liu, H.; Liu, L.; Sarina, S.; Zheng, Z.; Zhu, H. Silver oxide nanocrystals anchored on titanate nanotubes and nanofibers: Promising candidates for entrapment of radioactive iodine anions. Nanoscale 2013, 5, 11011-11018. [CrossRef] [PubMed]

33. Jose, M.; Sienkiewicz, P.; Szymanska, K.; Darowna, D.; Moszynski, D.; Lendzion-Bielun, Z.; Szymanski, K.; Mozia, S. Influence of Preparation Procedure on Physicochemical and Antibacterial Properties of Titanate Nanotubes Modified with Silver. Nanomaterials 2019, 9, 795. [CrossRef]

34. Rahimnejad, S.; He, J.H.; Pan, F.; Lee, X.; Chen, W.; Wu, K.; Xu, G.Q. Enhancement of the photocatalytic efficiency of WO 3 nanoparticles via hydrogen plasma treatment. Mat. Res. Express 2014, 1, 045044. [CrossRef]

35. Yun-Ju, L.; Barrera, D.; Luo, K.; Hsu, J.W.P. In situ chemical oxidation of ultrasmall $\mathrm{MoO}_{\mathrm{x}}$ nanoparticles in suspensions. J. Nanotechnol. 2012, 2012, 195761.

36. Kiatkittipong, K.; Scott, J.; Amal, R. Hydrothermally synthesized titanate nanostructures: Impact of heat treatment on particle characteristics and photocatalytic properties. ACS Appl. Mater. Interfaces 2011, 3, 3988-3996. [CrossRef] [PubMed]

37. Mendez-Galvan, M.; Celaya, C.A.; Jaramillo-Quintero, O.; Muniz, J.; Diaz, G.; Lara-Garcia, H.A. Tuning the band gap of M-doped titanate nanotubes ( $\mathrm{M}=\mathrm{Fe}, \mathrm{Co}, \mathrm{Ni}$, and $\mathrm{Cu})$ :an experimental and theoretical study. Nanoscale Adv. 2021, 3, 1382-1391. [CrossRef]

38. Fernandez-Werner, L.; Pignanelli, F.; Montenegro, B.; Romero, M.; Pardo, H.; Faccio, R.; Mombru, A.W. Characterization of titanate nanotubes for energy applications. J. Energy Storage 2017, 12, 66-77. [CrossRef]

39. Li, L.; Liu, X.; Zhang, Y. Visible-light photochemical activity of heterostructured core-shell materials composed of selected Ternary titanates and ferrites coated by $\mathrm{TiO}_{2}$. Appl. Mater. Interfaces 2013, 5, 5064-5071. [CrossRef] [PubMed] 